\title{
A Step toward Realization of Vision 2030; Reduction in Child Mortality: New Evidence from South Asian Countries
}

\author{
Shazia Kousar ${ }^{1}$ \\ Mahwish Zafar ${ }^{2}$ \\ Saeed Ahmad Sabir \\ Ali Sajjad S $^{4}$
}

\begin{abstract}
The objective of this study is to investigate the impact of economic and social factors on child mortality in South Asian countries. Economic factors consist of economic growth, private and public health expenditures while social factors are comprised of access to improved water sources, access to improved sanitation facilities, and environmental quality. This study collected the data from World Development Indicators (WDI) over the period of 1967-2016. This study utilized Johnson co-integration test to investigate the long run co-integration. The study found that long-run co-integration exits among the modeled variables. The results of long-run co-integration recommend that Auto Regressive Distributive Lag (ARDL) is appropriate to examine the short-run relationship among the modeled variables. The study found that access to improve water and sanitation facilities, environmental quality, total health expenditure, and economic growth significantly and negatively affect child survival. Moreover, the study has also investigated private and public health expenditure on child mortality separately and found that the size of the impact of public health expenditure is greater than private health expenditure. This study guides the policy makers and international agencies that in order to meet the required rate of child mortality they should invest more in the health sector and should provide clean water, sanitation facilities to its residents. Moreover, the study recommends that the government should revise environmental policies to lower the child mortality rate.
\end{abstract}

JEL Classification: $J 13, L 95, A 11, A 12$

Keywords: Child mortality, Water, and sanitation, the ARDL model, Social factors, Economic factors.

\section{INTRODUCTION}

Approximately seven million children under the age of five years are dying every year in the world and more than $30 \%$ burden of these child deaths are concentrated in South Asia. Although the nine countries of South Asian are trying to reduce child mortality rate since 1990 , still they are too far from the targeted level. Child mortality has been reduced during 2000-2010 from 9.6 million to 7.6 million in the world but the Millennium Development Goal (MDG-4) to reduce child mortality rate by two-thirds between 1990 -2015 remained unattainable, specifically South Asian countries are far from targeted level of child survival (Hussain, Cassen, \& Dyson, 2006; Nasejje, Mwambi, \& Achia, 2015). It has been noted that 10 million children under five year age are still dying every year (Black et al., 2010) and the burden of these child deaths is increasingly concentrated in poor resourced nations and explicitly in South Asian countries (Boyle, Barnes, Buchman, \& Bennett, 2009). Therefore,

\begin{tabular}{|c|c|}
\hline JISR-MSSE & Volume 17 \\
\hline
\end{tabular}


the World Health Organization (WHO) declared agenda 2030 and adopted a resolution to reduce child mortality from 171 million to 100 million during 2010-2025 in order to achieve sustainable development in the world.

Like other sub-regions, the South Asian Countries tried to achieve MDGs and their performance in, poverty reduction, gender discrimination in primary enrolment and environmental degradation is remarkable but still, it ranked 2nd in the world with high infant and child mortality rate. Moreover, Pakistan is ranked 1st with the highest child mortality rate among South Asian countries. The severity of the problem can be analyzed with the help of Figure 1. In 2016, Pakistan (PAK) observed 79, India (IND), Bangladesh (BGD) and Sri Lanka (LKA) observed 43, 34 and 9 child deaths per 1000 live births. However, the global target is to reduce newborn mortality to 12 per 1000 live birth in South Asian countries by 2030 .

\section{Figure 1}

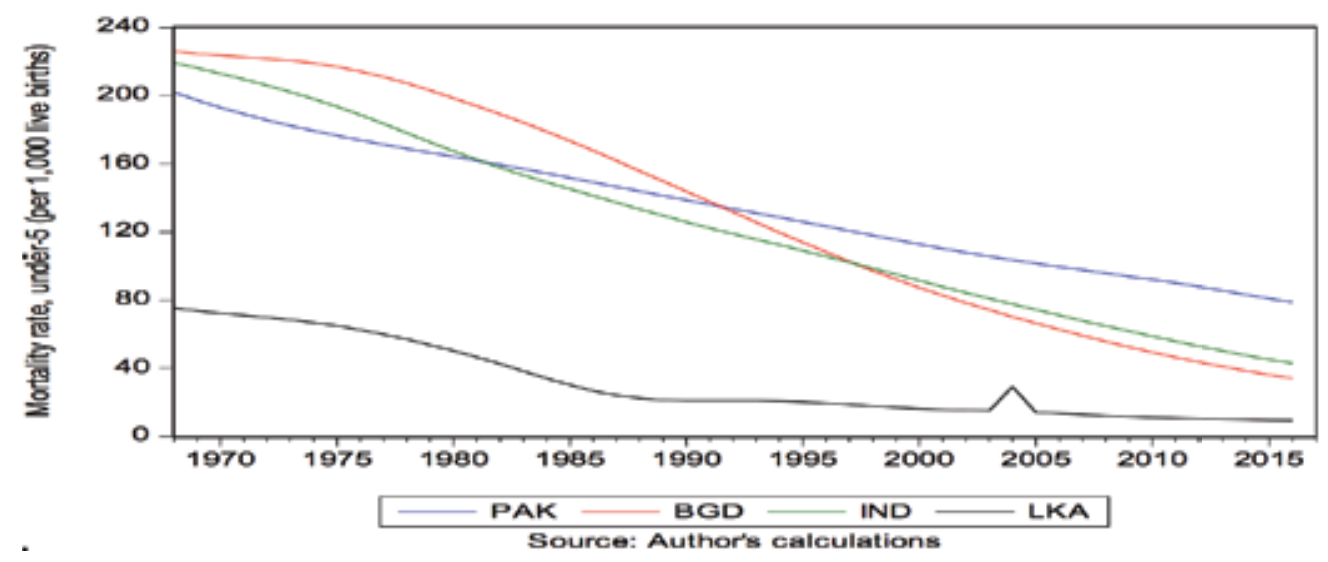

Therefore, this study is being carried with an ambition to contribute to global vision 2030 by identifying important socio-economic determinants that are strongly associated with child mortality. This study will help to design intervention strategies in South Asian countries to reduce child mortality rate which in turn will accelerate sustainable economic growth.

Most of the empirical literature focused the family-specific factors like maternal age , birth order, unclean cord care at the time of childbirth, failure of breastfeeding during the first 3 months of age, lack of immunizations, and previous infant or child death(s) in the family, while discussing the factor affecting child mortality (Kembo \& Van Ginneken, 2009; Singhi, Kumar, Raina, \& Kumar, 1989). Literature categories these factors as proximate factors because they directly contribute to child health and survival. However, social and economic factors like private and public health expenditures, economic growth, environmental quality, and improved water and sanitation facilities that may operate behind proximate determinants must be taken into account while investigating the factors affecting child mortality rate.

Almost 30,000 children under the age of 5 years are dying every day in poor nations because of poverty, low economic growth rate, and preventable infectious diseases (Caldwell, 1979; Hall \& Woolard, 2012), especially, in South Asian countries, high child mortality rate is 
strongly associated with low economic growth rate (Kraft, Nguyen, Jimenez-Soto, \& Hodge, 2013). Contrary, substantial decline in child mortality in Vietnam, Bangladesh, and Cambodia during the last decades advocates that child mortality rate can be reduced quickly without having high economic growth (Phuong, Huong, Tien, Chi, \& Dunne, 2013). Moreover, during the period of 1990 to 2011, adverse economic conditions and little improvement in education and health care in Iraq, Myanmar, and central Asian countries cause to slow down the rate of child survival in these countries, so overall the role of economic growth in child mortality is chaotic in the empirical literature and need to be reinvestigated.

Moreover, it has been observed that access to unimproved water and sanitation among children under 5 years old is a serious public health problem in many developing countries, including South Asia (Nakamura, Ikeda, Stickley, Mori, \& Shibuya, 2011). The children are more vulnerable to health hazards associated with an unimproved water supply and sanitation because their immune, respiratory, and digestive system is still at developing stage (Osita Kingsley Ezeh, Agho, Dibley, Hall, \& Page, 2015). Despite the importance of clean water and sanitation facilities, a few studies have investigated the role of clean water and sanitation facilities on child mortality in developing countries (Abou-Ali, 2003; Bampoky, 2013). Similarly, it has been observed that rich countries are spending more on health infrastructure than poor nations (Vapattanawong et al., 2007). Adequate and efficient public health spending is considered inevitable to reduce child mortality but is given low priorities in poor nations (Obrist et al., 2007). The provision of the health workforce, improved health infrastructure and allocation of a significant proportion of the total annual budget is necessary to improve child survival.

Unfortunately, in South Asian countries resources are scarce and being at initial stages of growth, the government is spending more on development activities at the expense of the nation's health. Most of the public health systems are operating at a small scale and their poor performance is responsible for high child mortality rate (Garcia, Pence, \& Evans, 2008). Figure 2 indicates the total public health expenditure in South Asian countries.

\section{Figure 2}

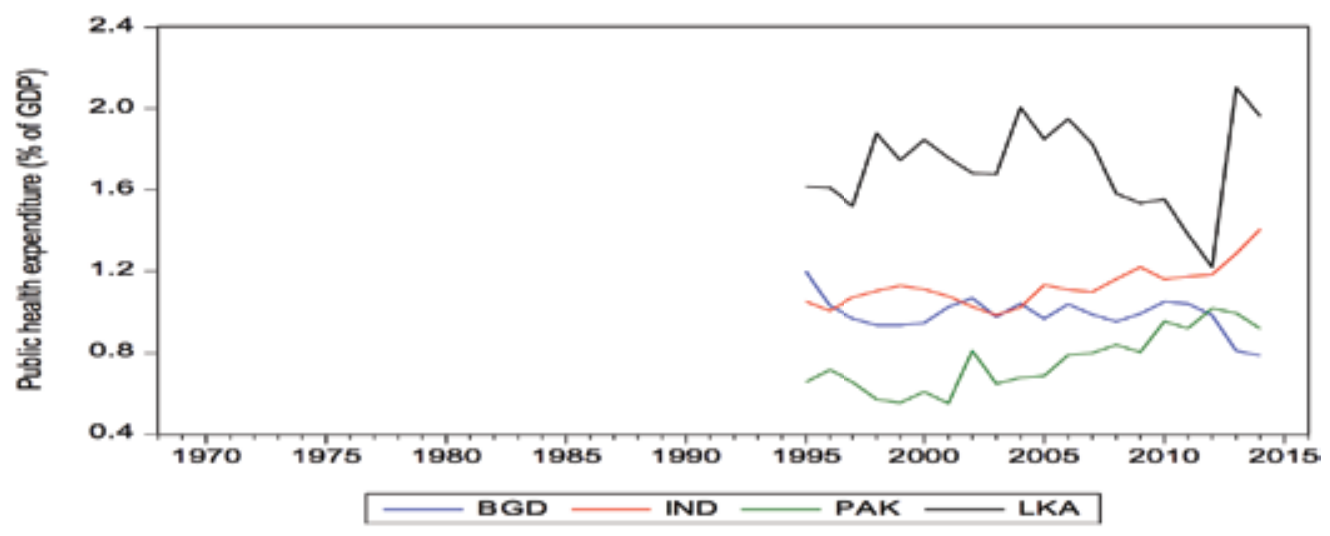

Source: Authors own calculation 
In BGD, IND, PAK, and LKA, public health expenditures (\% of GDP) are 0.79, 1.41, 0.92 and 1.96 respectively which is less than Sub Sahara Africa and Latin America (Novignon \& Lawanson, 2017). If public health expenditure in South Asian countries has a positive impact on child survival, which seems likely, then the exceptionally low level of public health expenditure indicates a potentially large opportunity (Barenberg, Basu, \& Soylu, 2015) to increase child survival. However, existing literature has a diverse opinion regarding the relationship between public health expenditure and child mortality rate. Some studies (Dutta \& Husain, 2012; Kaur \& Misra, 2003), documented that public health expenditure has little effect on health outcome while some studies investigated the positive association between public health expenditure and child survival (Barenberg et al., 2015; Farahani, Subramanian, \& Canning, 2010). Therefore, this study revisits the effect of public health expenditure on child mortality in South Asian context, so intervention policies can be devised to lower the child mortality under the age of five years.

During the last few decades, the growth pattern of south Asian countries indicates that increased level of economic growth is attributed to high consumption of commercial energy, which is generated out of continuous combustion of fossil fuels (Gray et al., 2006). Approximately $75 \%$ of all $\mathrm{CO} 2$ emissions during the last 20 years resulted from the burning of fossil fuels and the rest from deforestation (Outlook, 2008); which bring drastic climatic changes and social problems in South Asia region. Although, Kuznets curve describes the relationship between economic growth and environmental degradation (emission of $(\mathrm{CO} 2)$ but it ignores social sustainability aspects. It has been observed that South Asian countries are at the preindustrial stage, so they are trying to achieve high economic development at the cost of environmental degradation that affects its population's health. Infants and children absorb negative externalities that are associated with environmental degradation more quickly than elders. Therefore, it will be useful for policymakers to investigate the relationship between environmental quality and child mortality.

Therefore, this research is being conducted for three reasons; first to identify the social and economic factors that help the policymakers to achieve vision 2030, second to confirm the role of national income and improved water and sanitation facilities on child mortality for the south Asian countries and third is to introduce important and neglected economic determinant of child mortality like private, public health expenditure, and quality of environment. The deep understanding of these factors causes to reduce the menace of incessant childhood mortality in South Asian countries. Moreover, new scientific evidence will help the policy makers to understand predisposing factors associated with child mortality in South Asia and help them to develop appropriate policy interventions to reduce child policy mortality in this region.

\section{Research Questions}

1. What is the impact of economic development on child mortality?

2. What is the impact of private health expenditure on child mortality?

3. What is the impact of public health expenditures on child mortality?

4. What is the impact of improved water source on child mortality?

5. What is the impact of improved sanitation facilities on child mortality?

6. What is the impact of environmental quality on child mortality? 


\section{LITERATURE REVIEW}

The child mortality rate under age five is a significant indicator of a country socioeconomic welfare. The Importance of child mortality under age five can be estimated that it is on fourth position in Millennium Development Goal (MDGs), which were settled in 1990. According to MDGs world must have to decrease the child mortality up to 31 deaths per 1000 live births. The overall world had made considerable improvement from the period of 1990 but many developing countries had not achieved enough success for reducing child mortality rate under age five. Therefore, WHO announced Sustainable Development Goals (SDGs) and defined that child mortality under five has to be reduced 12 deaths per 1000 live births up to 2030 . Ample research is available on parental and biological determinant while the literature on indirect determinant, social and economic, is rare. Moreover, a few research articles are available in the context of South Asia.

\section{Economic Growth and Child Mortality}

The economic growth of a country is an invincible determinant to reduce child mortality under the age of five. Hanmer, Lensink, and White (2003) found that the increase in income has a negative relation with child mortality under the age of five in developing countries. So as income of the nation decreases the child mortality under the age of five increases. However, in Middle Eastern countries and African countries, it has been observed that child mortality rate has been declined along with a reduction in economic growth. It implies that income is not the single variable that affects the child mortality; there are some other factors that affect the child mortality (Cutler, Deaton, \& Lleras-Muney, 2006; Shehzad, 2006).

Moreover, Franz and FitzRoy (2006) found in 61 developing countries that fertility rate affects child mortality significantly. This study also uses health expenditure, income distributions, and nutrition as the main determinant of child mortality. However, this study neglects environmental quality and access to improved water and sanitation facilities which are an important factor that can affect child mortality in developing countries.

A few studies observed that child mortality rate decreases when economic growth increase (Van den Berg, Lindeboom, \& Portrait, 2006) but some studies found that economic growth is not a powerful determinant of child mortality because it has low and in some cases no association with child mortality (Filmer, 1999; Maruthappu et al., 2017). Especially in low-income countries where political and local administration is corrupt and give low priority to social indicators (Shehzad, 2006).

$\mathrm{H}_{1}=$ There is a relationship between economic growth and child mortality.

\section{Health Expenditure and Child Mortality}

According to the human development index, health is the most important determinant of the development of a country. The health of a resident of the country indicates the health expenditure priorities of its political and local governments. Although health expenditures affect the child mortality rate, the impact may be different in different regions.

As Hanmer et al. (2003), found that in developing countries private spending in health is ineffective and does not play a robust role to reduce child mortality while public health 
spending plays a great role to reduce child mortality. Contrary Filmer, Hammer, and Pritchett (2000) found that public health expenditure has a small impact on child mortality rate. The study argued that health expenditure explains less than one-seventh of $1 \%$ of the observed differences in child mortality rate across countries. Another study (Shehzad, 2006), discusses the impact of household income and education on child mortality. The study found that income and education have an inverse or negative relationship with child mortality. It implies that the increase of household income causes to increase their purchasing power and increases the chances to avail medical facilities that may cause of good health and help to reduce child mortality. The results of this study also support the Grossman's efficiency hypothesis and Chicago-Columbia hypothesis which discuss the impact of private income and education on child mortality.

Another study Issa and Ouattara (2005) discussed the impact of health expenditures on child mortality using 160 countries data and period of 1980-2000; the study found that health expenditures have a strong negative relationship with child mortality under the age of five years. The study found that the strength of the relationship varies from low-income countries to high-income countries. The results show that public health spending has a highly negative association with child mortality in high-income countries while the association is weak in low-income countries. However, the study found that private spending does not significantly associate with child mortality.

Contrary Gupta, Verhoeven, and Tiongson (2003), found that the effect of public health expenditure affect child mortality significantly in low-income countries while private health spending affects child mortality significantly in high-income countries. Moreover, lower health expenditure does not significantly affect the child mortality while big investment in health department extensively reduces the child mortality (Razum \& Breckenkamp, 2007; Yaya et al., 2017). Therefore, literature is not clear about the relationship of the public, private health expenditure, and child mortality and need to research. So, this study developed the following three important hypotheses on the basis of this relationship.

$\mathrm{H}_{2}==$ There is a relationship between public health expenditure and child mortality $\mathrm{H}_{3}==$ There is a relationship between private health expenditure and child mortality

\section{Environment Quality and Child Mortality}

Climatic change causes to spread different problems like smoke abatement, occupational disease, air pollution, and water pollution and contribute to public health hazards in a country. Literature used different indicators of environmental quality including the emission of $\mathrm{CO} 2$ from the burning of fossil fuels, Agricultural methane emissions, $\mathrm{CO} 2$ emissions from all transport activity (Meij et al., 2009). The air pollution is normally measured in the quantity of carbon dioxide is present in the air or the rate of carbon dioxide mixed in the air. The existence of $\mathrm{CO} 2$ in the air represents the true picture of health-related issues in a country. Empirical literature includes $\mathrm{CO} 2$ in the list of those important factors that have a strong indirect impact on child mortality under the age of five (Fitrianto, Hanafi, \& Chui, 2016)). Contrary, some studies found that air pollution, the existence of $\mathrm{CO} 2$, have week relation with child mortality (Gangadharan \& Valenzuela, 2001). 
During the period of industrialization $(1870$ - 2005), the concentration of carbon dioxide $(\mathrm{CO} 2)$ has been increased up to $35 \%$ in the atmosphere. To control the emission of $\mathrm{CO} 2$ and greenhouses gases, national and international government made an agreement at the national and international level to improve the quality of the environment. Similarly, an international conference held in Kyoto, Japan, and Kyoto Protocol was developed. Kyoto Protocol is a commitment from the concerned Parties to achieve internationally binding emission reduction targets. The conference agreed to reduce global warming by reducing green gases which consist of carbon dioxide (CO2), methane (CH4), nitrous oxide (N2O); and three fluorinated gases (F. gases), F. gases are man-made gases that can stay in the atmosphere for centuries and contribute to a global greenhouse effect, that are hydrofluorocarbons (HFCs), perfluorocarbons (PFCs), sulfur hexafluoride (SF6) and nitrogen trifluoride (NF3). These greenhouse gases are increasing in temperature near to $0.60 \mathrm{C}$ in the global average surface temperature since 1900 (Herzog, 2009).

The governments of Pakistan recognize the importance of the Kyoto Protocol and signed the agreement to reduce global warming in 2005 and formed the policy essential for proper implementation of this agreement in the country. Pakistan is producing $68 \%$ electricity from petroleum and $51 \%$ from the gas; both of these emit a high level of carbon dioxide (Haider, Khokhar, Chishtie, RazzaqKhan, \& Hakeem, 2017). Therefore, the high child mortality rate in Pakistan indicates that the impact of environmental quality on child mortality rate should be investigated in order to have appropriate policies to reduce the child mortality rate. Environmental pollution affects the environment directly and child mortality indirectly. Usually, carbon dioxide takes as the major factor that disturbs the environment. Therefore, environmental degradation like $\mathrm{CO} 2$, chemical pollution in the environment, the use of pesticide in the agriculture sector has serious implications for long-term public health (Jaga \& Dharmani, 2003).

$\mathrm{H}_{4}=$ There is a relationship between environmental quality and child mortality.

\section{Improved Water and Sanitation Facilities and Child Mortality}

Literature documented that improved water and sanitation facilities have a significant impact on childhood mortality (Osita K Ezeh, Agho, Dibley, Hall, \& Page, 2014; Günther \& Fink, 2010). A recent large cross-sectional study (Fink, Günther, \& Hill, 2011), investigated the relationship between improved water and sanitation facilities and child mortality in developing countries and found that almost $20 \%$ child mortality reduction take place due to access to improved water and sanitation facilities. Moreover, 2.2 million deaths in children aged less than 5 years old in low and middle-income countries have been prevented by providing them water and sanitation facilities.

Globally it has been noticed in developed economies that a local government commitment to improve water and sanitation facilities increases investment for improved water, sanitation and hygiene that caused a remarkable improvement in human living standard and hygiene practices (Alemu, 2017; Fewtrell et al., 2005). Contrary in south Asian countries picture is different and more than 134 million people of South Asia are living without having access to improved water and sanitation facilities while millions have limited access to safe water services and practice poor hygiene behaviors, it may be the leading causes of high child mortality and morbidity in South Asian countries (Lawn, Cousens, Zupan, \& Team, 2005).

\begin{tabular}{llll}
\hline JISR-MSSE & Volume 17 & Number 1 & January-June 2019 \\
\hline
\end{tabular}


Moreover, 64 to 84 percent of water sources are polluted in South Asia. Although South Asian countries achieved more than a 30 percent reduction in open excretion still 610 million people in South Asia used open places for excretion. Therefore, contaminated drinking and sanitation water cause water-borne diseases the newborn and mothers. Consequently, 25,000 children under five are dying every day in Sub Saharan Africa and South Asia which is 29 times greater than in industrialized countries: in South Asia, child death is 175 per 1000children while in industrialized countries it is 6 per 1000 .

Therefore, it is a need of time to investigate the impact of water and sanitation on childhood mortality to develop effective community mobilization and interventions; aimed to lower unimproved water and sanitation-related deaths.

$\mathrm{H}_{5}=$ There is a relationship between improved water facilities and child mortality

$\mathrm{H}_{6}=$ There is a relationship between improved sanitation facilities and child mortality

\section{THEORETICAL FRAMEWORK}

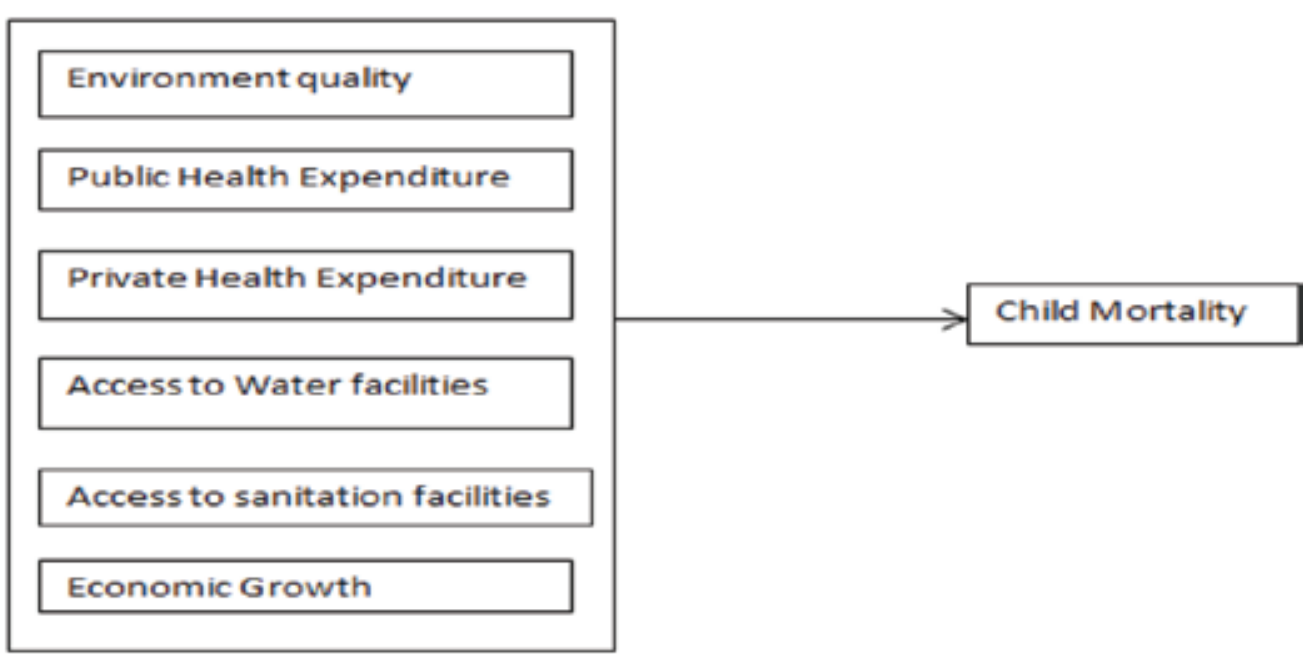

\section{THEORIES BEHIND CONCEPTUAL FRAMEWORK}

\section{Modernization Theory}

Modernization theorists stated a negative relationship between economic development and child mortality (Rostow, 1960). As economic development increases, it will foster the improvement of human well beings by providing better education, health, water and sanitation facilities that significantly lower the child mortality. Moreover, national and international empirical literature strongly recommended positive relationship between industrialization and human wellbeing (Bradshaw \& Fraser, 1989; Frey \& Field, 2000; Pendleton \& Yang, 1985). This study considers economic growth, health service (private and public) and public services like clean water and sanitation facilities as the major determinant of child mortality. 


\section{Development State Theory}

Development state theorist believes that state is an impotent actor to provide basic facilities of education, health and other public services that are helping to meet the basic need of the individuals and the society (Bronfenbrenner \& Evans, 2000). Several theorists argued that developed states are in a better position to pursue the policies that increase human welfare and reduces poverty (Moon \& Prasad, 1994). Improved public policies and reduction in poverty ultimately lowers the child mortality rate at the national level. Empirical literature also supported that wealthier nations are healthier nations (Hertzman, 2001; Pritchett \& Summers, 1993).

\section{Theory of Population and Environment Outlined}

The theory of population and environment outlined based on demographic transition theory. Demographic transition theory postulated that economic and social development causes to shift the society from high to low mortality and fertility growth rate. The theory stated that before a decline in fertility, first the child mortality rate will decline and eventually fertility and mortality both stabilize at the lower level and demographic transition cycle completes (Blake, 1965). However, the opponent argued that demographic transition theory has been developed on the experience of Western European and North American countries while in developing economies it becomes easy to stabilize the child mortality rate but it is very difficult to stabilize the fertility rate. Demographic theory in its glance that demographic transition causes to increase education and health opportunities is conceived as a part of the general theory of modernization.

Furthermore, economist and sociologist are in the view that natural resources and biophysical environment affect the demographic process through sociocultural and economic conditions. Therefore, demographic transition theory can be redefined after incorporating the environment changes which emerges due to change in the demographic transition. Therefore, New proposed theory of population and environment stated that relationship between population, development, and environment is inseparable. New theory hypothesized that environment degradation also causes the demographic transition. As Kuznets environment curve stated that as economic development increases it will cause to reduce environment quality. Bad environment quality will cause to increase child mortality (Gangadharan \& Valenzuela, 2001).

\section{Ecological System Theory}

Ecological system theory was proposed by Bronfenbrenner (1979) to explain the determinant of child health. The theory stated five systems like Microsystem, Mesosystem, Exosystem, Macrosystem, and Chronosystem, are significantly affect children's health. Therefore, environmental and biological factors are responsible for children health outcome. Ecological system theory recommends two types of factors; internal and external factors that affect child health and development. Internal factors are related to prenatal exposure to substances, premature birth, temperament, developmental delays, chronic medical conditions, and insecure attachments and contribute to children poor development and behavioral disorder. However, among external factors, environmental risk factors are prominent which affect child development and wellbeing. 


\section{DATA SOURCE AND METHODOLOGY}

\section{Data Sources}

This study used secondary data to investigate the role of economic and social factors in child mortality. This study collected the data from the world development indicators (WDI) for GDP growth (annual \%), private and public health expenditure (\% of GDP), improved water and sanitation facilities ( $\%$ of population with access), three indicators for environment quality like emission of CO2 from the burning of fossil fuels, Agricultural methane emissions, CO2 emissions from all transport activity and child mortality rate under the age of five years over the period of 1967-2016. There are eight South Asian countries but this study selects four South Asian countries, Bangladesh, India, Pakistan and Sri Lanka for investigation while this study has excluded Bhutan, Afghanistan, Nepal, and Maldives due to unavailability of data.

To maintain a strategic distance from the spurious regression, we need to test the time-series characteristics of all variables and figure out whether variables are stationary or not. This study used Leven Lin \& Chu (Levin, Lin, \& Chu, 2002) and IPS panel unit root test to check the order of integration in modeled variables. This study used the general structure of panel unit root testing procedures that are:

$$
\Delta y_{i t}=\beta_{0 i}+p_{i} y_{i t-1}+\sum_{i=0}^{p i} \beta_{1 i} \Delta y_{i t-j}+\propto_{i} d_{i t}+\mu_{i, t}
$$

In the equation, $d_{\mathrm{it}}$ indicates the deterministic components. If $p_{\mathrm{i}}=0$, it means the y process has a unit root for individual $i$ and $p i<0$ means that the process is stationary around the deterministic part.

Moreover, $\beta_{\mathrm{oi}}$ is the constant expression which is assumed to differ across cross-sectional elements while $\mathrm{p}$ is the identical autoregressive coefficient $\beta_{\mathrm{i}}$ depicts the lag order and $\mu_{\text {it }}$ shows the residual term

$$
\mu_{i, t}=\sum_{i=0}^{p i} \beta_{1 i} \Delta y_{i t-j}+\epsilon_{i, t}
$$

Panel unit root test is used to check, whether the data is stationary at a level or at first difference. Panel unit root test applied with both individual intercept and individual intercept $\&$ trend at a level and first difference and results are reported in tables.

\section{Econometric Model}

In order to examine the impact of private, public health expenditure, improved water facilities, improved sanitation facilities, environmental quality and economic growth on child mortality for the region of South Asia, this study specifies the two ARDL models with three equations for each model. Model 1 investigates the short run and long run association of private health expenditure and child mortality with three different proxies of environmental quality into three different equations while model 2 examines to the association between public health expenditure and child mortality with three different proxies of environment quality into three different equations. Model 4 estimates the impact of total health expenditure, and environmental quality along with GDP, IWF, and ISF on child mortality.

10 January-June $2019 \quad$ Volume $17 \quad$ Number $1 \quad$ JISR-MSSE


MODEL 1.

$$
\begin{aligned}
\Delta M O R_{S A}=\alpha_{1}+ & \sum_{i=1}^{p} \beta_{1} \Delta \mathrm{CO}_{2 t-1}+\sum_{i=1}^{p} \beta_{2} \Delta I W F_{t-1}+\sum_{t=1}^{p} \beta_{3} \Delta I S F_{t-1}+\sum_{i=1}^{p} \beta_{4} \Delta H P R_{t-1}+\sum_{t=1}^{p} \beta_{5} \Delta G D P_{t-1} \\
& +\lambda_{1} \mathrm{CO}_{2 t-1}+\lambda_{2} I W F_{t-1}+\lambda_{3} I S F_{t-1}+\lambda_{4} H P R_{t-1}+\lambda_{5} G D P_{t-1}+u_{1 t}--E q .1 \\
\Delta M O R_{S A}=\alpha_{1}+ & \sum_{i=1}^{p} \beta_{1} \Delta \mathrm{CO}_{2} \operatorname{tran}_{t-1}+\sum_{i=1}^{p} \beta_{2} \Delta I W F_{t-1}+\sum_{i=1}^{p} \beta_{3} \Delta I S F_{t-1}+\sum_{i=1}^{p} \beta_{5} \Delta H P R_{t-1} \\
& +\sum_{i=1}^{p} \beta_{7} \Delta G D P_{t-1}+\lambda_{1} \mathrm{CO}_{2} \text { trans }_{t-1}+\lambda_{2} I W F_{t-1}+\lambda_{3} I S F_{t-1}+\lambda_{4} H P R_{t-1}+\lambda_{5} G D P_{t-1} \\
& +\lambda_{8} D S C L_{t-1}+u_{1 t}----E q .2 \\
\Delta M O R_{S A}=\alpha_{1}+ & \sum_{i=1}^{p} \beta_{1} \Delta \mathrm{CO}_{2} \mathrm{agri}_{t-1}+\sum_{i=1}^{p} \beta_{2} \Delta I W F_{t-1}+\sum_{i=1}^{p} \beta_{3} \Delta I S F_{t-1}+\sum_{i=1}^{p} \beta_{4} \Delta H P R_{t-1} \\
& +\sum_{i=1}^{p} \beta_{5} \Delta G D P_{t-1}+\lambda_{1} \mathrm{CO}_{2} \mathrm{agri}_{t-1}+\lambda_{2} I W F_{t-1}+\lambda_{3} I S F_{t-1}+\lambda_{4} H P R_{t-1}+\lambda_{5} G D P_{t-1} \\
& +u_{1 t}-----E q .3
\end{aligned}
$$

MODEL 2.

$$
\begin{aligned}
& \begin{aligned}
\Delta M O R_{S A}=a_{1}+ & \sum_{i=1}^{p} \beta_{1} \Delta C O_{2 t-1}+\sum_{i=1}^{D} \beta_{2} \Delta I W F_{t-1}+\sum_{i=1}^{D} \beta_{3} \Delta I S F_{t-1}+\sum_{i=1}^{D} \beta_{4} \Delta H P B_{t-1}+\sum_{i=1}^{p} \beta_{5} \Delta G D P_{t-1} \\
& +\lambda_{1} \mathrm{CO}_{2 t-1}+\lambda_{2} I W F_{t-1}+\lambda_{3} I S F_{t-1}+\lambda_{4} H P B_{t-1}+\lambda_{5} G D P_{t-1}+u_{1 t}=-E q .4
\end{aligned} \\
& \Delta M O R_{s A}=a_{1}+\sum_{i=1}^{p} \beta_{1} \Delta \mathrm{CO}_{2} \mathrm{agri}_{t-1}+\sum_{i=1}^{D} \beta_{2} \Delta I W F_{t-1}+\sum_{i=1}^{D} \beta_{3} \Delta I S F_{t-1}+\sum_{i=1}^{D} \beta_{4} \Delta H P B_{t-1} \\
& +\sum_{i=1}^{p} \beta_{5} \Delta G D P_{t-1}+\lambda_{1} \mathrm{CO}_{2} \operatorname{agri}_{t-1}+\lambda_{2} I W F_{t-1}+\lambda_{3} I S F_{t-1}+\lambda_{4} H P B_{t-1}+\lambda_{5} G D P_{t-1} \\
& +u_{1 t}=--E q .5 \\
& \Delta M O R_{S A}=a_{1}+\sum_{i=1}^{p} \beta_{1} \Delta C O_{2} \text { trans }_{t-1}+\sum_{t=1}^{p} \beta_{2} \Delta I W F_{t-1}+\sum_{t=1}^{p} \beta_{3} \Delta I S F_{t-1}+\sum_{t=1}^{p} \beta_{4} \Delta H P B_{t-1}
\end{aligned}
$$

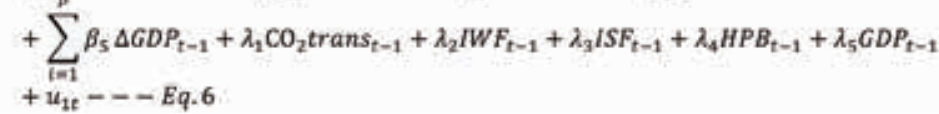

In the above equation, $\Delta \mathrm{MOR}_{\mathrm{SA}}$ represents child mortality in South Asia. The term represents the constant term of south Asian countries including Pakistan, India, Sir Lanka, and Bangle Dash. IWF and ISF represent improved water and sanitation facilities, HPR represent private health expenditures, HPB shows public health expenditures, GDP represents economic growth, and $\mathrm{CO} 2$ represents the emission of carbon dioxide from the burning of fossil fuels, $\mathrm{CO} 2$ agri. represent agricultural methane emissions, CO2trans, represents emissions of carbon dioxide from all transport activity, all these three proxies are included to capture environmental quality. All the variables used in the above equations are related to South Asian countries. Where $\mu_{\text {it }}$ show the residual term, $\beta_{1,} \beta_{2,} \beta_{3,} \beta_{4}$ and $\beta_{5}$, show the coefficients of equation $1,2,3,4,5$, and 6 in short run of respective variables. 


\section{RESULTS AND DISCUSSION}

This study used Leven Lin \& Chu (LLC) (Levin, Lin et al. 2002) and Im Pesaran and Shin (IPS) panel unit root test to check the order of integration in modeled variables.

Table 1. Unit Root Test

\begin{tabular}{lll}
\hline Variables & LLC & IPS \\
\hline $\mathrm{CM}$ & $-7.55692 * * *$ & $-3.54812 * * *$ \\
$\mathrm{D}\left(\mathrm{CO}_{2}\right)$ & $-4.39823 * * *$ & $-5.69949 * * *$ \\
$\mathrm{CO}_{2} \mathrm{TRANS}$ & $-2.60245 * * *$ & $-2.37003 * * *$ \\
$\mathrm{D}\left(\mathrm{CO}_{2} \mathrm{AGRI}\right)$ & $-4.60245 * * *$ & $-13.8829 * * *$ \\
$\mathrm{GDP}$ & $-2.80995 * * *$ & $-6.27600 * * *$ \\
$\mathrm{HEPRI}$ & $-1.58724 * *$ & $-1.30582 * *$ \\
$\mathrm{D}(\mathrm{HEPUB})$ & $-1.31054 *$ & $-3.49644 * * *$ \\
$\mathrm{ISF}$ & $-1.75663 * * *$ & $-5.21161 * * *$ \\
$\mathrm{IWF}$ & $-6.57240 * * *$ & $-2.92402 * * *$ \\
\hline
\end{tabular}

$* * *, * *, *$ represents significance at $1 \%, 5 \%, 10 \%$

The results of the unit root test indicate that D (HEPUB), D (CO2AGRI) and D (CO2) are stationary at first difference while other variables are stationary at level.

Table 2. Correlation Analysis

The results of correlation analysis indicate that private and public health expenditure is highly correlated

\begin{tabular}{|c|c|c|c|c|c|c|c|c|c|}
\hline & $\mathrm{CM}$ & GDP & HEXPPRI & HEXPPUB & ISF & IWF & $\mathrm{CO2}$ & AGRIC02 & CO2TRANS \\
\hline$\overline{\mathrm{CM}}$ & 1 & & & & & & & & \\
\hline GDP & -0.10 & 1.00 & & & & & & & \\
\hline HEXPPRI & 0.15 & 0.29 & 1.00 & & & & & & \\
\hline HEXPPUB & -0.04 & 0.10 & -0.94 & 1.00 & & & & & \\
\hline ISF & -0.28 & -0.10 & -0.46 & 0.80 & 1.00 & & & & \\
\hline IWF & 0.14 & 0.00 & 0.27 & -0.29 & -0.05 & 1.00 & & & \\
\hline $\mathrm{CO}_{2}$ & 0.56 & 0.24 & 0.44 & -0.45 & -0.42 & 0.18 & 1.00 & & \\
\hline $\mathrm{AGRICO}_{2}$ & 0.22 & 0.20 & -0.08 & -0.37 & -0.34 & -0.22 & 0.96 & 1.00 & \\
\hline CO2TRANS & -0.52 & -0.23 & -0.37 & 0.67 & 0.56 & 0.03 & -0.89 & -0.64 & 1.00 \\
\hline
\end{tabular}

and their correlation value is above than .70. This study used three proxy variables like CO2, agriCO2 and $\mathrm{CO} 2$ transport to indicate the environment quality. Results indicate that these proxy variables are highly correlated with each other. Therefore, in order to control multicollinearity, this study estimated six equations. 
Table 3. Descriptive Statistics

\begin{tabular}{llllllllll}
\hline & CM & CO2 & GDP & HEPRI & HEPUB & ISF & IWF & CO2trans & CO2 agri \\
\hline Mean & 73.957 & 0.206 & 5.346 & 2.227 & 1.130 & 49.105 & 82.327 & 3.100 & 72.088 \\
Median & 83.600 & 0.176 & 5.149 & 2.035 & 1.035 & 44.200 & 82.000 & 3.017 & 72.219 \\
Maximum & 126.000 & 0.419 & 9.801 & 3.419 & 2.006 & 89.600 & 90.100 & 4.218 & 83.497 \\
Minimum & 12.200 & 0.073 & -1.545 & 1.282 & 0.552 & 20.800 & 72.100 & 2.342 & 63.897 \\
Std. Dev. & 36.992 & 0.110 & 2.094 & 0.611 & 0.404 & 21.500 & 5.453 & 0.610 & 5.832 \\
Jarque- & 5.736 & 5.888 & 4.507 & 4.614 & 5.106 & 6.041 & 4.219 & 4.666 & 2.880 \\
Bera & $(0.067)$ & $(0.06)$ & $(0.10)$ & $(0.100)$ & $(0.078)$ & $(0.07)$ & $(0.12)$ & $(0.097)$ & $(0.23)$ \\
Obs. & 56.000 & 56.000 & 56.00 & 56.000 & 56.000 & 56.00 & 56.00 & 56.000 & 56.00 \\
\hline
\end{tabular}

The descriptive statistics show that average private and public health care expenditure as a percentage of GDP in South Asian countries are approximately $2.227 \%$ and $1.130 \%$ and results also indicate that private health expenditure on average is greater than public health expenditures. However, total health expenditures are $3.357 \%$ which are less than total health expenditure (average 10\% of GDP) in Sub Sahara Africa (Novignon, Olakojo, \& Nonvignon, 2012), while child mortality had a mean of about 73 infant deaths per 1000 live births that is much higher than Russia (59\%) and USA (14\%) (You, Hug, Ejdemyr, \& Beise, 2015). Approximately $49 \%$ and $82 \%$ of the population had access to improved sanitation facilities and improved water source, respectively. On average, Carbon dioxide emissions from the burning of fossil fuels is 0.206 metric tons per capita while agricultural methane emissions from animals are 72.088 thousand metric tons of $\mathrm{CO} 2$ equivalent and $\mathrm{CO} 2$ emissions from transport are $3.100 \%$ of total fuel combustion. Moreover, on average GDP per capita growth is $5.346 \%$ annually. The values of Jarque-Bera indicate that data is normally distributed and can be used for further analysis.

Table 4. Kao Residual Co-integration Test

\begin{tabular}{lll}
\hline Null Hypothesis: No cointegration & & \\
\hline ADF & t-Statistic & Prob. \\
& -2.771878 & 0.0028 \\
& & \\
Residual variance & 7.663447 & \\
HAC variance & 8.446415 & \\
\hline
\end{tabular}

This study employed the residual cointegration test to test the long run cointegration among the modeled variables and results are reported in table 4 . Results indicate that there is significant long-run cointegration among the modeled variables. Therefore the ARDL model is appropriate to investigate the short-run relationship. 
Table 5. Panel ARDL: Long Run Results (Dependent Variable: Child Mortality)

\begin{tabular}{|c|c|c|c|c|c|c|}
\hline \multirow[t]{3}{*}{ Independent variables } & \multicolumn{6}{|c|}{ Selected Model: ARDL $(1,2,2,2,2,2)$} \\
\hline & & Model. 1 & & & Model. 2 & \\
\hline & Eq.1 & Eq. 2 & Eq.3 & Eq. 1 & Eq.2 & Eq.3 \\
\hline GDP & $-2.09 * * *$ & $0.67 * * *$ & -0.12 & -0.03 & $-1.55 * * *$ & $-1.29 * * *$ \\
\hline HEXPPRI & -2.32 & $-3.41 * * *$ & $-8.16^{* * *}$ & & & \\
\hline HEXPPUB & & & & $-26.8 * * *$ & $-6.72 * * *$ & $-12.5 * * *$ \\
\hline ISF & $-1.12 * * *$ & $-2.21 * * *$ & $-3.23 * * *$ & $-2.14 * * *$ & $-1.70 * * *$ & 0.07 \\
\hline IWF & $0.66 * *$ & $8.36^{* * *}$ & $2.410 * * *$ & $2.05^{* * *}$ & $1.46 * * *$ & -0.34 \\
\hline $\mathrm{CO} 2$ & $197.8 * * *$ & & & $533.3 * * *$ & & \\
\hline CO2Trans & & $111.5^{* * *}$ & & & $3.53 * * *$ & \\
\hline Agr. CO2 & & & $0.49 * * *$ & & & $0.89 * * *$ \\
\hline $\operatorname{ECT}(-1)$ & $-0.130 * * *$ & $-0.02 * * *$ & $-0.06^{* *}$ & $-0.048 * *$ & $-0.20 * * *$ & $-0.23 * * *$ \\
\hline
\end{tabular}

$* * *, * *, *$ represents significance at $1 \%, 5 \%, 10 \%$

Table 6. Panel ARDL: Short Run Results (Dependent Variable: Child Mortality)

\begin{tabular}{|c|c|c|c|c|c|c|}
\hline \multirow[t]{3}{*}{ Independent variables } & \multicolumn{6}{|c|}{ Selected Model: ARDL $(1,2,2,2,2,2)$} \\
\hline & \multicolumn{3}{|c|}{ Model. 1} & \multicolumn{3}{|c|}{ Model. 2} \\
\hline & Eq.1 & Eq. 2 & Eq.3 & Eq. 1 & Eq.2 & Eq.3 \\
\hline $\mathrm{D}(\mathrm{GDP})$ & 0.145 & -0.21 & 0.35 & 0.10 & 0.20 & -0.25 \\
\hline $\mathrm{D}(\mathrm{GDP}(-1))$ & 0.25 & $0.10^{* *}$ & 0.29 & 0.34 & 0.21 & \\
\hline D(HEXPPRI) & 1.04 & 2.23 & -5.84 & & 2.78 & \\
\hline D(HEXPPRI $(-1))$ & 5.34 & 7.01 & 3.68 & & 2.28 & \\
\hline D(HEXPPUB) & & & & 0.57 & & 3.97 \\
\hline D(HEXPPUB(-1)) & & & & -4.32 & & \\
\hline $\mathrm{D}$ (ISF) & -1.35 & -1.77 & 22.20 & -7.34 & 5.09 & -2.72 \\
\hline $\mathrm{D}(\mathrm{ISF}(-1))$ & -17.28 & -19.42 & 31.32 & -9.27 & -7.73 & \\
\hline $\mathrm{D}(\mathrm{IWF})$ & -3.32 & -8.50 & 10.68 & 1.96 & -8.44 & 16.64 \\
\hline $\mathrm{D}(\mathrm{IWF}(-1))$ & -14.80 & -12.41 & -20.63 & -21.58 & -13.70 & \\
\hline $\mathrm{D}(\mathrm{CO} 2)$ & 73.01 & & & 158.16 & & \\
\hline $\mathrm{D}(\mathrm{CO} 2(-1))$ & -144.79 & & & -93.46 & & \\
\hline D(CO2TRANS) & & 4.22 & & & -3.82 & \\
\hline D(CO2TRANS(-1)) & & 11.15 & & & 4.25 & \\
\hline D(AGRICO2) & & & -0.31 & & & -0.47 \\
\hline $\mathrm{D}(\mathrm{AGRI}(\mathrm{CO} 2(-1))$ & & & $0.042 * * *$ & & & \\
\hline $\mathrm{C}$ & 50.6 & 39.9 & -44.3 & 36.6 & 40.05 & -29.07 \\
\hline
\end{tabular}

The result of ARDL model indicates that GDP has significant and negative relationship with child mortality in equation, $1,2,4$, and 6 [( -2.093139 (0.0001), -0.675674 (0.0013), $-1.555865(0.0000),-1.296837(0.0226)]$ while in equation 3 and 4 it has insignificant association with child mortality [(-0.121988 (0.6656), $-0.035403(0.8853)$. Results indicate that as total national income increase it will cause to reduce child mortality under the age of five years. So, this study determines that income is a significant determinant of child survival in South Asian countries. When the national income of a country increases, it will cause to 
increase the employment opportunities and household income level. Higher household income level induces the individual to enjoy better nutrition, improved living condition and accessible upgraded health opportunities (Konteos, Katrakilidis, \& Sotiriadou, 2018), which ultimately reduces the child mortality. Moreover, higher income countries are in a better position to offer health and education opportunities and to pursue public policies to increase the welfare of human beings. The foundation of good health of society depends on the income of the economy. It has been documented that the overall health of the community depends on the average income of the country (Marmot, 2002). Moreover, it has been observed that in low-income countries child mortality rate is greater as compared to the high-income countries.

Similarly, results indicate that private health expenditure significantly and negatively associated with child mortality in equation 2 and 3 while it is insignificant in equation $1,[-3.416371(0.0194),-8.163361(0.0000),[-2.321980(0.3055)]$. However, the public health expenditure has a significant and negative association with child mortality in all three equations [-26.85704 (0.0002), -6.729624 (0.000), -12.59172 (0.0300)]. Moreover, the extent of the effect of public health expenditure is greater than the extent of the impact of private health expenditure on child mortality. Our results are consistent with Gani (2008) who have found significant and negative relationship between child mortality and total health expenditures but are contradicting with Issa and Ouattara (2005), Paxson and Schady (2005) and Novignon and Nonvignon (2012) who found the negative and significant association with child mortality but the extent of the effect of private health expenditure is higher than that of public health expenditure on the infant mortality rate. In the early twentieth century, when health services and technologies were limited; the child mortality rate was tried to control through improved nutrition, education facilities but later on government introduced immunizations and antimicrobial interventions along with more health opportunities to reduce the child mortality rate. Similarly n South Asian countries the size of impact of public health expenditure is greater because in low-income countries, National Health Service system is run by the ministry of health and they allocate a basic package of public health service for the entire population, some level of financial protection against calamitous illness to the poor segments of the population (Xu et al., 2003).

Moreover, result of equation $1,2,3,4$ and 5 [-1.124715 (0.0002), -2.212036 (0.0000), $-3.238720(0.0000),-2.140606(0.0000), 1.709349(0.0001)]$ indicates that as the access to improved sanitation facilities will significantly lower child mortality. Our results are consistent with Barber et al. (2017), who have found that improved sanitation is a significant influencing factor to reduce the infant mortality rate. This implies that improved sanitation facilities increase child resistance capacity against infectious diseases. However, the result of equation $1,2,3,4$ and 5 [0.665876 (0.0425), 8.361943 (0.0000), 2.410329 (0.0007), 2.052262 $(0.0185), 1.469972(0.0022)]$ indicate that access to improved water significantly and positively affect child mortality rate. The results of this study are similar to Condran and Crimmins-Gardner (1978), who has investigated the relationship between the provision of water filtration and child mortality rate in Philadelphia. The study found that although child mortality from typhoid fever has been declined child mortality from other diseases like diarrhea, dysentery, and enteritis which are waterborne diseases, did not decline. In South Asian countries, almost $18 \%$ of childhood deaths are caused by diarrhea and $20 \%$ by acute respiratory infections, both are water-related diseases. 
Furthermore, this study has investigated the relationship of environmental quality, measured by emission of $\mathrm{CO} 2$ from the burning of fossil fuels and the manufacture of cement, emission of $\mathrm{CO} 2$ from transport activities and emission of methane from agriculture, and child mortality and study found that as emission of $\mathrm{CO} 2$ from the burning of fossil fuels, Agricultural methane emissions, $\mathrm{CO} 2$ emissions from all transport activity will increase it will cause to increase child mortality rate under the age of five years. It has been observed that in low-income countries, environment degradation play important role in child survival Anderson, Romani, Phillips, and Van Zyl (2002) and more than 1 in 4 deaths of children less than 5 years of age are attributed to air pollution and second-hand smoke. Moreover, organs and immune systems of the children, being at the developing stage are badly affected by the polluted environment and make them more vulnerable to the negative impacts of dirty air. Even polluted environment start to affect the children in the mother's womb and increase the risk of premature birth. Additionally, exposure of infants and pre-scholars to air pollution increases the risk of pneumonia in children, chronic respiratory diseases, such as asthma and risk of heart disease, stroke, and cancer (WHO, 2017 March, 6).

\section{CONCLUSION}

Socio-economic variables (e.g., economic growth, public, and private health expenditure, and access to improved water and sanitation facilities, environment quality) are proximate factors (indirect contributors) that affect the health of a community overall and specifically have a high influence on morbidity and child mortality level. This study found that as economic prosperity in South Asian countries increases, it causes to reduce child mortality. Similarly public and private health expenditures have a negative and significant association with child mortality. However, the size of the impact of public health expenditure on child mortality is greater than private health expenditure. Moreover, access to improved sanitation facilities reduces child mortality significantly. However, access to improved water facilities has a significant positive association with child mortality. Results suggest that waterborne diseases like diarrhea, dysentery, and enteritis did not decline and causes to increase child mortality rate in South Asia. Similarly, the study found a strong positive and significant association between environmental quality and child mortality in South Asia region. However, the size of the impact of $\mathrm{CO} 2$ emission from the burning of fossil fuels and transport activities is greater than the emission of methane from agricultural activities. The results of this study guide the policymakers of South Asian countries that in order to reduce child mortality the government should invest more in public health expenditure and in development projects. Moreover, to improve environmental quality government should adopt more environmental regulations and provide greater facilities of improved water and sanitation facilities to the population, in order to reduce the child mortality rate.

\section{LIMITATION AND FUTURE RESEARCH DIRECTION}

This study selected only four south Asian countries like India, Pakistan, Bangladesh, and Sri Lanka for investigation the research problem while other countries, Bhutan, Afghanistan, Nepal and Maldives, have not been considered due to unavailability of data. Moreover, future researchers should investigate the topic in depth and conduct research for each individual country in South Asia to recommend policy suggestions for each individual country. Since each country in the South Asian region has different characteristics in terms of political and economic preferences; so an in-depth study is recommended.

\begin{tabular}{|c|c|}
\hline January-June 2019 & Volume 17 \\
\hline
\end{tabular}




\section{REFERENCES}

Abou-Ali, H. (2003). The effect of water and sanitation on child mortality in Egypt. rapport nr.: Working Papers in Economics (112).

Alemu, A. M. (2017). To what extent does access to improved sanitation explain the observed differences in infant mortality in Africa? African journal of primary health care \& family medicine, 9(1), 1-9.

Anderson, B. A., Romani, J. H., Phillips, H. E., \& Van Zyl, J. A. (2002). Environment, access to health care, and other factors affecting infant and child survival among the African and coloured populations of South Africa, 1989-94. Population and Environment, 23(4), 349-364.

Bampoky, C. (2013). Can clean drinking water and sanitation reduce child mortality in Senegal? Pepperdine Policy Review, 6(1), 3.

Barber, R. M., Fullman, N., Sorensen, R. J., Bollyky, T., McKee, M., Nolte, E., . . Abbas, K. M. (2017). Healthcare Access and Quality Index based on mortality from causes amenable to personal health care in 195 countries and territories, 1990-2015: a novel analysis from the Global Burden of Disease Study 2015. The lancet, 390(10091), 231-266.

Barenberg, A. J., Basu, D., \& Soylu, C. (2015). The effect of public health expenditure on infant mortality: Evidence from a panel of Indian states, 1983-84 to 2011-12: Working Paper, University of Massachusetts, Department of Economics.

Black, R. E., Cousens, S., Johnson, H. L., Lawn, J. E., Rudan, I., Bassani, D. G., . . Cibulskis, R. (2010). Global, regional, and national causes of child mortality in 2008: a systematic analysis. The lancet, 375(9730), 1969-1987.

Blake, J. (1965). Demographic science and the redirection of population policy. Journal of Chronic Diseases, 18(11), 1181-1200.

Boyle, P. A., Barnes, L. L., Buchman, A. S., \& Bennett, D. A. (2009). Purpose in life is associated with mortality among community-dwelling older persons. Psychosomatic medicine, 71(5), 574.

Bradshaw, Y. W., \& Fraser, E. (1989). City size, economic development, and quality of life in China: New empirical evidence. American Sociological Review, 54(6) 986-1003.

Bronfenbrenner, U. (1979). The ecology of human development: Harvard university press.

Bronfenbrenner, U., \& Evans, G. W. (2000). Developmental science in the 21st century: Emerging questions, theoretical models, research designs and empirical findings. Social development, 9(1), 115-125.

Caldwell, J. C. (1979). Education as a factor in mortality decline an examination of Nigerian data. Population studies, 33(3) 395-413.

Condran, G. A., \& Crimmins-Gardner, E. (1978). Public health measures and mortality in US cities in the late nineteenth century. Human Ecology, 6(1), 27-54.

Cutler, D., Deaton, A., \& Lleras-Muney, A. (2006). The determinants of mortality. Journal of economic perspectives, 20(3), 97-120.

De Onis, M., Dewey, K. G., Borghi, E., Onyango, A. W., Blössner, M., Daelmans, B., . . . Branca, F. (2013). The World Health Organization's global target for reducing childhood stunting by 2025: rationale and proposed actions. Maternal \& child nutrition, 9, 6-26.

Dutta, M., \& Husain, Z. (2012). Use of hospital services and socio-economic status in urban India: Does health insurance ensure equitable outcomes? 
Ezeh, O. K., Agho, K. E., Dibley, M. J., Hall, J., \& Page, A. N. (2014). The impact of water and sanitation on childhood mortality in Nigeria: evidence from demographic and health surveys, 2003-2013. International Journal of Environmental Research and Public Health, 11(9), 9256-9272.

Ezeh, O. K., Agho, K. E., Dibley, M. J., Hall, J. J., \& Page, A. N. (2015). Risk factors for postneonatal, infant, child and under-5 mortality in Nigeria: a pooled cross-sectional analysis. BMJ open, 5(3), e006779.

Farahani, M., Subramanian, S., \& Canning, D. (2010). Effects of state-level public spending on health on the mortality probability in India. Health economics, 19(11), 1361-1376.

Fewtrell, L., Kaufmann, R. B., Kay, D., Enanoria, W., Haller, L., \& Colford Jr, J. M. (2005). Water, sanitation, and hygiene interventions to reduce diarrhoea in less developed countries: a systematic review and meta-analysis. The Lancet infectious diseases, 5(1), 42-52.

Filmer, D. (1999). Child mortality and public spending on health: How much does money matter? : The World Bank.

Filmer, D., Hammer, J. S., \& Pritchett, L. H. (2000). Weak links in the chain: a diagnosis of health policy in poor countries. The World Bank Research Observer, 15(2), 199-224.

Fink, G., Günther, I., \& Hill, K. (2011). The effect of water and sanitation on child health: evidence from the demographic and health surveys 1986-2007. International journal of epidemiology, 40(5), 1196-1204.

Fitrianto, A., Hanafi, I., \& Chui, T. L. (2016). Modeling Asia's Child Mortality Rate: A Thinking of Human Development in Asia. Procedia Economics and Finance, 35(2), 249-255

Franz, J. S., \& FitzRoy, F. (2006). Child mortality and environment in developing countries. Population and environment, 27(3), 263-284.

Frey, R. S., \& Field, C. (2000). The determinants of infant mortality in the less developed countries: a cross-national test of five theories. Social Indicators Research, 52(3), 215-234.

Gangadharan, L., \& Valenzuela, M. R. (2001). Interrelationships between income, health and the environment: extending the Environmental Kuznets Curve hypothesis. Ecological Economics, 36(3), 513-531.

Gani, A. (2008). Health care financing and health outcomes in Pacific Island countries. Health policy and planning, 24(1), 72-81.

Garcia, M. H., Pence, A., \& Evans, J. (2008). Africa's future, Africa's challenge: early childhood care and development in Sub-Saharan Africa: The World Bank.

Gray, G. E., Van Niekerk, R., Struthers, H., Violari, A., Martinson, N., McIntyre, J., \& Naidu, v. (2006). The effects of adult morbidity and mortality on household welfare and the well-being of children in Soweto. Vulnerable Children and Youth Studies, 1(1), 15-28.

Günther, I., \& Fink, G. (2010). Water, Sanitation and Children's Health. Prospects.

Gupta, S., Verhoeven, M., \& Tiongson, E. R. (2003). Public spending on health care and the poor. Health economics, 12(8), 685-696.

Haider, K., Khokhar, M. F., Chishtie, F., RazzaqKhan, W., \& Hakeem, K. R. (2017). Identification and future description of warming signatures over Pakistan with special emphasis on evolution of CO 2 levels and temperature during the first decade of the twenty-first century. Environmental Science and Pollution Research, 24(8), 7617-7629.

Hall, K., \& Woolard, I. (2012). Children and inequality: An introduction and overview: Children's Institute. 
Hanmer, L., Lensink, R., \& White, H. (2003). Infant and child mortality in developing countries: analysing the data for robust determinants. The Journal of Development Studies, 40(1), 101-118.

Hertzman, C. (2001). Health and human society: Wealthier nations are not always healthier, and efforts to improve health can be swamped by the effects of inequality and conflict. American Scientist, 89(6), 538-545.

Herzog, T. (2009). World greenhouse gas emissions in 2005. World Resources Institute.

Hussain, A., Cassen, R., \& Dyson, T. (2006). Demographic transition in Asia and its consequences. ids Bulletin, 37(3), 79-87.

Issa, H., \& Ouattara, B. (2005). The effect of private and public health expenditure on infant mortality rates: does the level of development matters. Damascus Univ. J, 28(1), 21-37.

Jaga, K., \& Dharmani, C. (2003). Sources of exposure to and public health implications of organophosphate pesticides. Revista panamericana de salud pública, 14, 171-185.

Kaur, B., \& Misra, S. (2003). Social sector expenditure and attainments: An analysis of Indian states. Reserve Bank of India occasional papers, 24(1), 105-143.

Kembo, J., \& Van Ginneken, J. K. (2009). Determinants of infant and child mortality in Zimbabwe: Results of multivariate hazard analysis. Demographic Research, 21, 367-384

Konteos, G., Katrakilidis, C., \& Sotiriadou, K. (2018). Dynamic Linkages between Health and Wealth in the European Union. Theoretical Economics Letters, 8(04), 709.

Kraft, A. D., Nguyen, K.-H., Jimenez-Soto, E., \& Hodge, A. (2013). Stagnant neonatal mortality and persistent health inequality in middle-income countries: a case study of the Philippines. PLoS One, 8(1), e53696.

Lawn, J. E., Cousens, S., Zupan, J., \& Team, L. N. S. S. (2005). 4 million neonatal deaths: when? Where? Why? The lancet, 365(9462), 891-900.

Levin, A., Lin, C.-F., \& Chu, C.-S. J. (2002). Unit root tests in panel data: asymptotic and finite-sample properties. Journal of econometrics, 108(1), 1-24.

Marmot, M. (2002). The influence of income on health: views of an epidemiologist. Health affairs, 21(2), 31-46.

Maruthappu, M., Watson, R. A., Watkins, J., Zeltner, T., Raine, R., \& Atun, R. (2017). Effects of economic downturns on child mortality: a global economic analysis, 1981-2010. BMJ global health, 2(2), e000157.

Meij, J., Van Bodegom, D., Ziem, J., Amankwa, J., Polderman, A., Kirkwood, T., . . . Westendorp, R. (2009). Quality-quantity trade-off of human offspring under adverse environmental conditions. Journal of evolutionary biology, 22(5), 1014-1023.

Moon, C. i., \& Prasad, R. (1994). Beyond the developmental state: networks, politics, and institutions. Governance, 7(4), 360-386.

Nakamura, H., Ikeda, N., Stickley, A., Mori, R., \& Shibuya, K. (2011). Achieving MDG 4 in sub-Saharan Africa: what has contributed to the accelerated child mortality decline in Ghana? PLoS One, 6(3), e17774.

Nasejje, J. B., Mwambi, H. G., \& Achia, T. N. (2015). Understanding the determinants of under-five child mortality in Uganda including the estimation of unobserved household and community effects using both frequentist and Bayesian survival analysis approaches. BMC public health, 15(1), 1003.

Novignon, J., \& Lawanson, A. O. (2017). Health expenditure and child health outcomes in Sub-Saharan Africa. African Review of Economics and Finance, 9(1), 96-121. 
Novignon, J., \& Nonvignon, J. (2012). Socioeconomic status and the prevalence of fever in children under age five: evidence from four sub-Saharan African countries. BMC research notes, 5(1), 380 .

Novignon, J., Olakojo, S. A., \& Nonvignon, J. (2012). The effects of public and private health care expenditure on health status in sub-Saharan Africa: new evidence from panel data analysis. Health Economics Review, 2(1), 22.

Obrist, B., Iteba, N., Lengeler, C., Makemba, A., Mshana, C., Nathan, R., . . . Mayumana, I. (2007). Access to health care in contexts of livelihood insecurity: a framework for analysis and action. PLoS medicine, 4(10), e308.

Paxson, C., \& Schady, N. (2005). Child health and economic crisis in Peru. The World bank economic review, 19(2), 203-223.

Pendleton, B. F., \& Yang, S.-O. (1985). Socioeconomic and health effects on mortality declines in developing countries. Social Science \& Medicine, 20(5), 453-460.

Phuong, T. B., Huong, N. T., Tien, T. Q., Chi, H. K., \& Dunne, M. P. (2013). Factors associated with health risk behavior among school children in urban Vietnam. Global health action, 6(1), 18876.

Pritchett, L., \& Summers, L. H. (1993). Wealthier is healthier (Vol. 1150): World Bank Publications.

Razum, O., \& Breckenkamp, J. (2007). Mortality in Children under 5 years and social situation: International comparison. DEUTSCHES ARZTEBLATT-KOLN-, 104(43), 2520 .

Rostow, W. W. (1960). The stages of growth: A non-communist manifesto: Cambridge University Press.

Shehzad, S. (2006). The determinants of child health in Pakistan: an economic analysis. Social Indicators Research, 78(3), 531-556.

Singhi, S., Kumar, R., Raina, N., \& Kumar, V. (1989). Determinants of infant and child mortality in rural Haryana. The Indian Journal of Pediatrics, 56(6), 753-763.

Van den Berg, G. J., Lindeboom, M., \& Portrait, F. (2006). Economic conditions early in life and individual mortality. American Economic Review, 96(1), 290-302.

Vapattanawong, P., Hogan, M. C., Hanvoravongchai, P., Gakidou, E., Vos, T., Lopez, A. D., \& Lim, S. S. (2007). Reductions in child mortality levels and inequalities in Thailand: analysis of two censuses. The lancet, 369(9564), 850-855.

Yaya, S., Ekholuenetale, M., Tudeme, G., Vaibhav, S., Bishwajit, G., \& Kadio, B. (2017). Prevalence and determinants of childhood mortality in Nigeria. BMC public health, 17(1), 485.

You, D., Hug, L., Ejdemyr, S., \& Beise, J. (2015). Levels and trends in child mortality. Report 2015. Estimates developed by the UN Inter-agency Group for Child Mortality Estimation. 